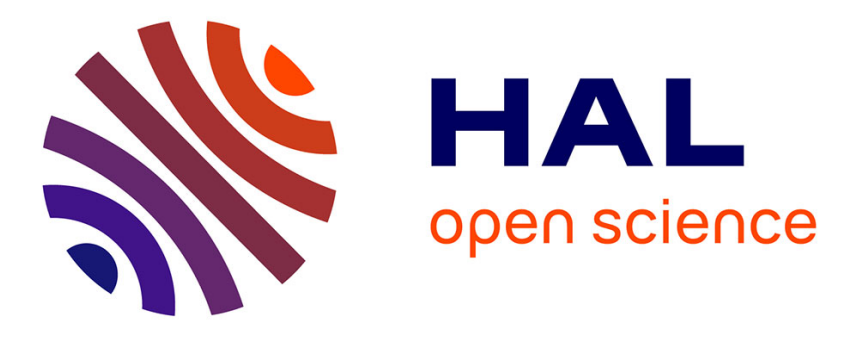

\title{
Dual-Band Transmitarray with Low Scan Loss for Satcom Applications
}

Kien Pham, Guang Liu, D. Gonzalez-Ovejero, Ronan Sauleau

\section{To cite this version:}

Kien Pham, Guang Liu, D. Gonzalez-Ovejero, Ronan Sauleau. Dual-Band Transmitarray with Low Scan Loss for Satcom Applications. IEEE Transactions on Antennas and Propagation, 2021, 69 (3), pp.1775-1780. 10.1109/tap.2020.3031410 . hal-03099318

\section{HAL Id: hal-03099318 \\ https://hal-univ-rennes1.archives-ouvertes.fr/hal-03099318}

Submitted on 6 Jan 2021

HAL is a multi-disciplinary open access archive for the deposit and dissemination of scientific research documents, whether they are published or not. The documents may come from teaching and research institutions in France or abroad, or from public or private research centers.
L'archive ouverte pluridisciplinaire HAL, est destinée au dépôt et à la diffusion de documents scientifiques de niveau recherche, publiés ou non, émanant des établissements d'enseignement et de recherche français ou étrangers, des laboratoires publics ou privés. 


\title{
Dual-Band Transmitarray with Low Scan Loss for Satcom Applications
}

\author{
Kien T. Pham, Guang Liu, David González Ovejero, and Ronan Sauleau
}

\begin{abstract}
This paper presents the experimental validation of independent and wide beam scanning with a dual-band transmitarray antenna (TA) in Satcom up- and down-links at Ka-band. The TA consists of two sub-arrays, one operates in the down-link with central frequency at 19.5 $\mathrm{GHz}$, while the other one operates in the up-link centered at $29 \mathrm{GHz}$. Both sub-arrays share a common radiating aperture to obtain compact configuration. The TA layout is made of 1-bit unit-cells and its design relies on the bifocal technique to extend the beam scanning capability. The proposed bifocal prototype includes 1500 up-link unit-cells in $\mathbf{3 0} \times \mathbf{5 0}$ matrix and 1581 down-link unit-cells arranged in $31 \times 51$ rectangular lattice. The 1D scanning is validated by displacing the feed horn along one direction. We show that the $\mathrm{TA}$ beam can be scanned in $\mathrm{a} \pm \mathbf{4 0 ^ { \circ }}$ and $\pm 30^{\circ}$ independently in each band while keeping a very low scan loss $(<2 \mathrm{~dB})$.
\end{abstract}

Index Terms - Bifocal, Satcom, dual-band, dual-polarization.

\section{INTRODUCTION}

Transmitarray antennas (TAs) are a mature alternative technology with some key advantages with respect to more standard solutions based on reflectors, phased arrays and reflectarrays. As compared to reflectarray antennas (RAs), which work in reflection mode, TAs operate in transmission mode and do not suffer from blockage from the feeder. They can be also easily integrated on moving platforms, for example, high speed trains, vehicles, drones, etc., without significant impact on their aerodynamic properties. In particular, TAs are considered as very promising candidates for Satcom on the move (SOTM) and 5G applications. The frequency bands allocated in Europe for SOTM applications (both civil and military) are $27.5 \mathrm{GHz}$ - $31 \mathrm{GHz}$ and $17.7 \mathrm{GHz}-21.2 \mathrm{GHz}$ for the up and down links, respectively [1]. The advantage of covering both bands with the same aperture is, hence, obvious.

Recent studies on TAs have demonstrated their performance at various frequency bands, e.g. [2]-[5], including also dual-polarization and dual-band capabilities, e.g. [6], [7]. Metal-only prototypes have been also introduced as lower cost solutions compared to their dielectric-based counterparts [8], [9]. Reconfigurable TAs (RTAs) with electronically steerable beams are also of strong interest owing to their 2D scanning capabilities over a wide angular field of view, typically beyond $\pm 50^{\circ}$ [10], [11]. However, RTAs or reconfigurable RAs require a significant number of solid state components to control their phase distribution on the radiating aperture, and their unit-cells architectures may become quite complex to route DC biasing lines [10]-[14]. Purely passive TAs can also be used to steer the beam in any arbitrary direction by mechanically displacing a feed horn in the TA focal plane [3] or by switching focal arrays [15]. The later architecture exhibits a limited field of view, while the feed in [3] is displaced over longer distances to reach a wider maximum scan angle, but at the expense of a quite high scan loss (around $5 \mathrm{~dB}$ at $\pm 30^{\circ}$ ) due

K. T. Pham is with School of Electrical Engineering, International University, Ho Chi Minh City, Vietnam and also with Vietnam National University, Ho Chi Minh City, Vietnam (e-mail: ptkien@hcmiu.edu.vn).

D. González-Ovejero, and R. Sauleau are Univ. Rennes, CNRS, IETR UMR 6164, F-35000 Rennes, France. (e-mail: david.gonzalez-ovejero@univrennes1.fr, ronan.sauleau@univ-rennes1.fr).

G. Liu was with IETR, UMR CNRS 6164, Université de Nantes, Polytech Nantes. He is now with Key Laboratory of Microwave Remote Sensing, National Space Science Center, Chinese Academy of Sciences, Beijing 100190, China (e-mail: guang.liu@univ-nantes.fr, liuguang@mirslab.cn). to the higher spill-over radiation and phase aberration [3]. Recently, a 1D TA in parallel plate waveguide provided $\pm 42^{\circ}$ beam-scanning in the H-plane by switching the focal source. In this configuration, the number of beams equals the number of ports [16]. Therefore, significant efforts are being devoted to obtaining wide angle scanning and low scan loss simultaneously.

The design procedure of RAs and TAs is similar, except for operation in reflection or transmission. Hence, we provide next an overview on RA and TA structures with an improved scan range. One possibility consists in introducing a bifocal architecture to expand the scanning range of RAs [17]-[18] and TAs [19]. The designs in [17][18] obtain the phase distribution on the RA aperture as the average phase of two foci associated to two beam directions; optimization algorithms are also applied to overcome the limitations of unifocal and bifocal techniques. On the other hand, the weighted average approach is used in [19]. This technique takes into account a Gaussian weight function on the aperture in order to obtain low aberration in both phase and illumination level. The scanning loss is reported to be less than 1$\mathrm{dB}$ for a scanning range of $\pm 30^{\circ}$ in [18] and around $2.8 \mathrm{~dB}$ for a $0^{\circ}$ to $50^{\circ}$ scanning in [19]. A recent dual-band TA in circular polarization with wide beam scanning (up to $50^{\circ}$ with scan loss below $3.6 \mathrm{~dB}$ ) is reported in [7] for Ka-band Satcom. The TA structure consists of 6 substrates and 7 layers.

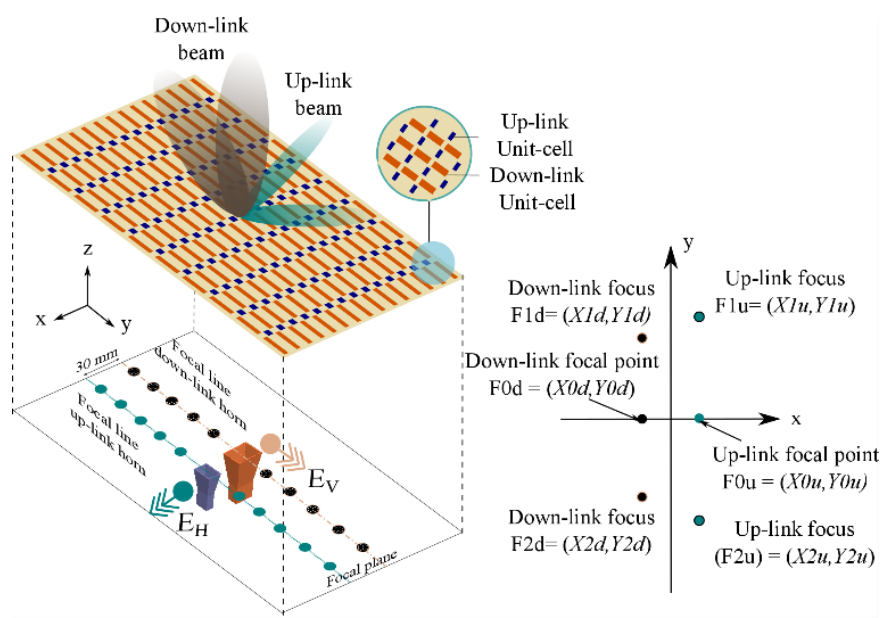

Fig. 1. Architecture of dual-band dual-linearly polarized bifocal TA with independent beam scanning, and its four focal points (right figure). The radiating aperture contains two independent sub-arrays operating in the down link (in orange) and in the up-link (in blue). Green and dark dots illustrate the positions of the up- and down-link horns displaced in the focal plane to steer the beam.

The main objective of this paper is to present an experimental demonstration on scanning loss reduction for dual-band TA, as alternative to the work reported in [6], and to extend scanning range in comparison with [18]-[20] with the additional freedom of tilting the beam in either up- or down-link for arbitrary directions. The simplified design procedure presented in this work for dual-band operation is an advantage with respect to [20] for light-weight TA.

The antenna architecture and main design rules are described in Section II. The fabricated prototypes and measurement results are presented in Section III to validate the proposed concept. Conclusions are drawn in Section IV.

\section{ACCEPTED MANUSCRIPT}




\section{BifocAl TransmitarRay IN DUAL-BAND Operation}

The purpose of the proposed TA configuration is to provide independently two arbitrary beams pointing to any direction while each beam operates in either up- or down-link. These beams are able to operate simultaneously or alternatively. The detailed architecture of the proposed antenna is illustrated in Fig. 1. This schematic includes a dual-band TA, which layout is calculated to provide two independent linearly-polarized (LP) pencil beams. The TA is illuminated with two separate feeding sources (the pyramidal horns shown in Fig. 1), which are displaced individually in the focal plane to steer the beams individually in each band.

The concept used here for dual-band operation is based on the interleaving technique already introduced by the authors in [6]. This technique consists in interleaving two independent LP TA sub-arrays in the same radiating aperture. Each sub-array operates in orthogonal polarization and in a different frequency band. The use of LP unitcells strongly-decoupled in the down- and up-link leads to a very simple design procedure, as described in [6]: both down- and up-link sub-transmitarrays are designed individually and their layout are superimposed to form the dual-band radiating aperture. We introduce here an improved design by combining the interleaving technique [6] with the bifocal one [17], [18] to further improve the TA beam scanning performance.

More precisely, the up-link and down-link arrays are made of 30by-50 and 31-by-51 elements arranged in a rectangular lattice, as illustrated in Fig. 1. The unit-cells are square with periodicity of $6 \mathrm{~mm}$ to be compatible with array interleaving [6]. The unit-cells include two narrow radiating patches connected by a via-hole structure and separated by a ground. These three metal layers are printed on two identical 0.762-mm thick substrates (Roger Duroid RT6002). The detailed dimensions, characteristics of the up- and down-link unitcells are reported in Section III in [6] and not mentioned here for the sake of brevity.

In contrast to [6], the TA is extended along $y$-axis (corresponding to E-plane in the up-link and H-plane in the down-link) to reduce spillover loss for extreme tilt angles. The focal distance is set to $110 \mathrm{~mm}$ to maximize the antenna gain. The 10-dBi gain standard horns, similar to the ones in [6], are used to illuminate the TA aperture; they are offset by $+15 \mathrm{~mm}$ and $-15 \mathrm{~mm}$ along $\mathrm{x}$-axis for up-link and down-link respectively. Such an inter-horn spacing $(30 \mathrm{~mm})$ has been selected to ease their accommodation in the focal plane.

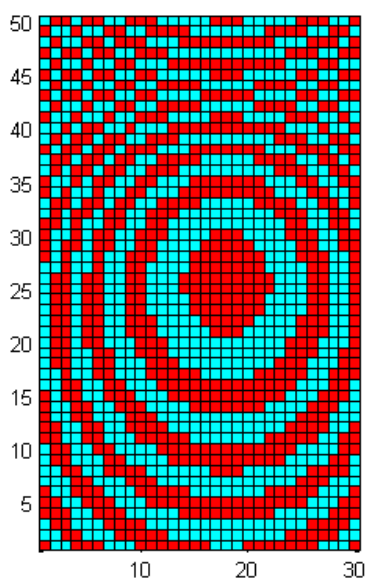

(a)

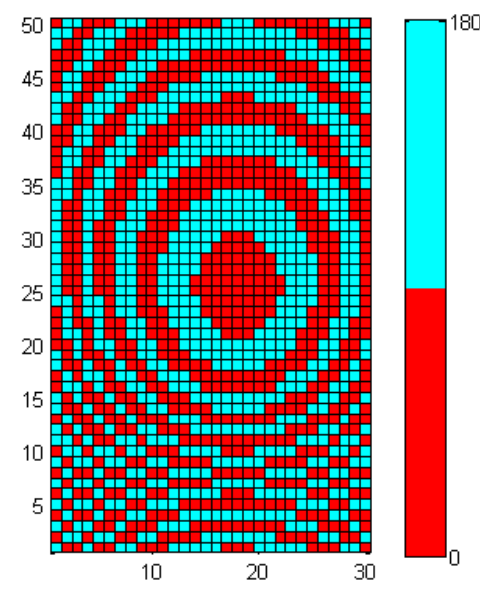

(b)
Fig. 2. Computed phase distribution (in deg.) on the TA aperture at $29 \mathrm{GHz}$ for up-link horn located at (a) $63.5 \mathrm{~mm}$ and (b) $-63.5 \mathrm{~mm}$ along $y$-axis, in order to radiate at $-30^{\circ}$ and $+30^{\circ}$ in E-plane, respectively.
The bifocal technique has been implemented here following the design procedure reported in [19], [20], in order to design the two desired interleaved bifocal sub-arrays in the up- and down links. The technique implemented here is modified to apply this dual-band TA (see Eq. (1) and Eq. (2) below). The initial parameters are taken from [6] for $D_{A, u}=180 \mathrm{~mm}, F_{u}=110 \mathrm{~mm}$ and $\tau_{\mathrm{u}}=0.6$ for edge illumination of $-12 \mathrm{~dB}$. The maximum gain is obtained at broadside or $\alpha_{0, u}\left(a_{0}=0\right)=0^{\circ}$. The two focal points $F 1 u$ and $F 2 u$ of the up-link subarray are located along its own focal line (Fig. 1), parallel to $y$-axis, symmetrically at $y=-63.5 \mathrm{~mm}$ and $y=+63.5 \mathrm{~mm}$; their coordinates are thus the following: $F 1 u=(15 \mathrm{~mm}, 63.5 \mathrm{~mm})$ and $F 2 u=(15 \mathrm{~mm}$, - $63.5 \mathrm{~mm})$; their positions, defined in Fig. 1, lead to two beams pointing at $\pm 30^{\circ}$. The phase and amplitude distributions on the subarray radiating aperture are plotted in Figs. 2 and 3, respectively, for each beam. As described in [17], these phase layouts have been averaged and combined to produce the final TA layout at $29 \mathrm{GHz}$ (Fig. $4 \mathrm{a}$ ), with the corresponding parameters $y_{i, u}=63.5 \mathrm{~mm}$ and $\alpha_{i, u}=30^{\circ}$ [17].

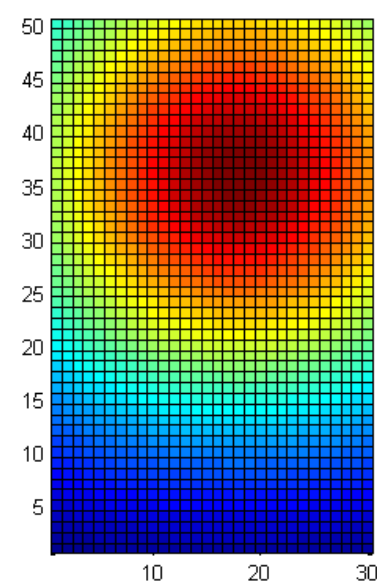

(a)

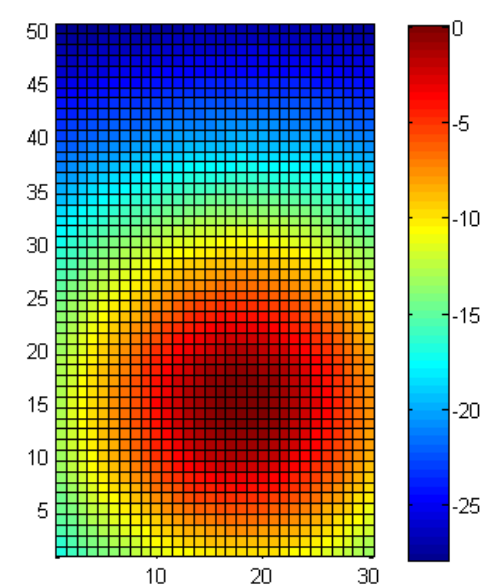

(b)
Fig. 3. Normalized illumination level (in $\mathrm{dB}$ ) on the TA aperture at $29 \mathrm{GHz}$ for up-link horn located at (a) $63.5 \mathrm{~mm}$ and (b) $-63.5 \mathrm{~mm}$ along y-axis, in order to radiate at $-30^{\circ}$ and $+30^{\circ}$ in E-plane respectively.

Here, the phase is optimized by averaging the phase aberration due to feed horn displacement. The bifocal phase distribution is calculated as follows [19]-[20]

$$
\varphi_{T A}{ }^{\text {bif }}=\frac{1 \varphi_{1}^{\text {uif }}+A_{2} \times \varphi_{2}^{\text {uif }}}{A_{1}+A_{2}},
$$

where $A_{1}$ and $A_{2}$ are the illumination levels of the incident wave and are used as weight coefficients for the corresponding unifocal phase layouts $\varphi_{1}^{\text {uif }}$ and $\varphi_{2}^{\text {uif }}$.

In turn, the unifocal phase layouts above are computed as follows

$$
{ }_{i j}^{u i f}: \frac{u}{d}=k_{0}\left(y \sin \alpha_{i}-\sqrt{\left(x-x_{0}^{u / d}\right)^{2}+\left(y-y_{i}^{u / d}\right)^{2}+F^{2}}\right)
$$

where $u / d$ stands for uplink/downlink array respectively

The same procedure has been applied in the down link, assuming that both focal points are located at $F 1 d=(-15 \mathrm{~mm}, 51.5 \mathrm{~mm})$ and $F 2 d$ $(-15 \mathrm{~mm},-51.5 \mathrm{~mm})$ and generate two beams pointing at $\pm 25^{\circ}$ in elevation. The corresponding parameters of [17] are $y_{i, d}=51.5 \mathrm{~mm}$ and $\alpha_{i, d}=25^{\circ}$. The final layout at $19.5 \mathrm{GHz}$ is provided in Fig. $4 \mathrm{~b}$.

\section{ACCEPTED MANUSCRIPT}




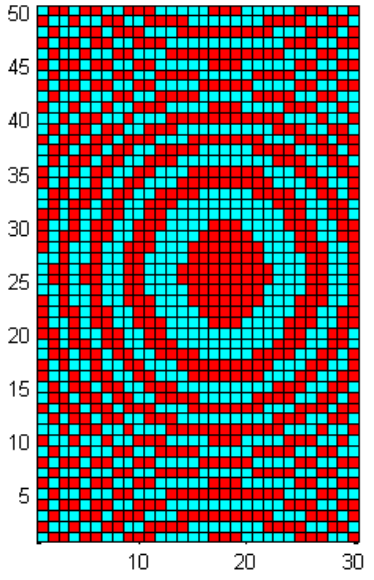

(a)

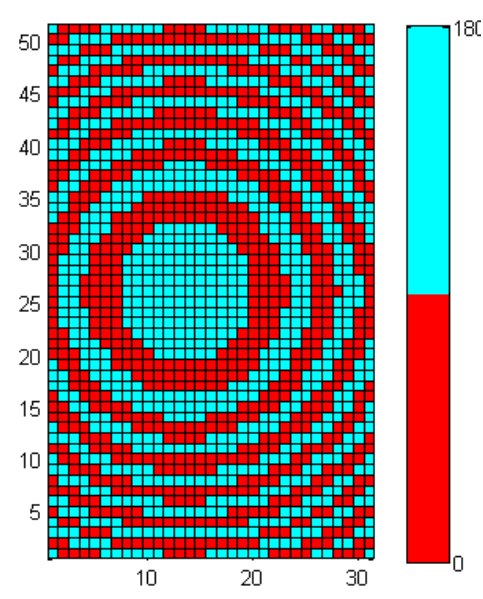

(b)

Fig. 4. Bifocal layouts of the dual-band TA at (a) $29 \mathrm{GHz}$ and (b) $19.5 \mathrm{GHz}$ respectively.

The parameters used for the design proposed here are summarized in Table I.

TABLE I

MAIN DESIGN PARAMETERS USING THE PARAMETERS DEFINED IN [19],[20]

\begin{tabular}{c|c|c}
\hline \hline Parameters & $\begin{array}{c}\text { Down-link @ 19.5 } \\
\mathrm{GHz}\end{array}$ & Up-link @ 29 GHz \\
\hline$D_{A}$ & $186 \mathrm{~mm}$ & $180 \mathrm{~mm}$ \\
$y_{1 / y_{2}}$ & $-51.5 \mathrm{~mm} / 51.5 \mathrm{~mm}$ & $-63.5 \mathrm{~mm} / 63.5 \mathrm{~mm}$ \\
$\alpha_{1 / \alpha_{2}}$ & $25^{\circ} /-25^{\circ}$ & $30^{\circ} /-30^{\circ}$ \\
\hline \hline
\end{tabular}

One can notice that the unifocal phase layouts for the up- and downlink are computed separately since they are independent and the feed-horns positions for the up- and down-links are also different $\left(x_{o}^{u}=+15 \mathrm{~mm}\right.$ and $\left.x_{o}^{d}=-15 \mathrm{~mm}\right)$, as shown in Fig. 1.

\section{EXPERIMENTAL RESULTS}

To better demonstrate the enhanced performance of the bifocal prototype, a unifocal dual-band TA has been also designed, with the same aperture size, unit-cell type and F/D ratio as the bifocal TA described in Section II. Fig. 5a and Fig. 5b show the down- and uplink layouts computed at $19.5 \mathrm{GHz}$ and $29 \mathrm{GHz}$, respectively.

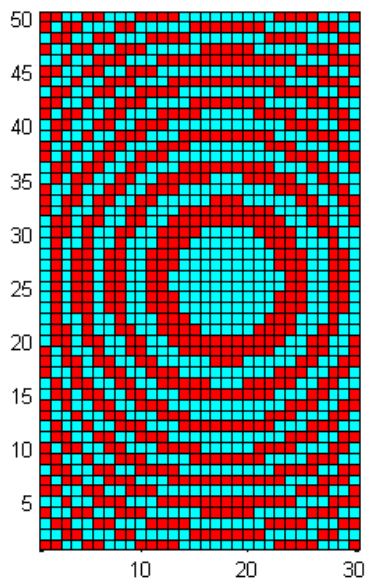

(a)

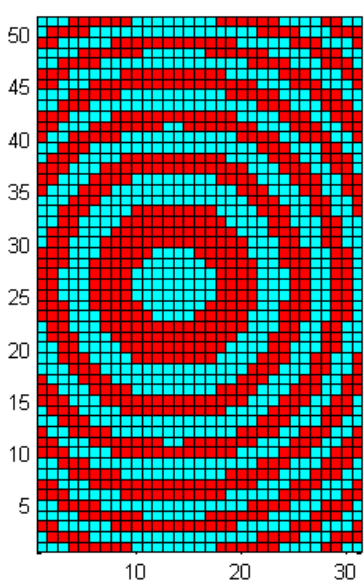

(b)

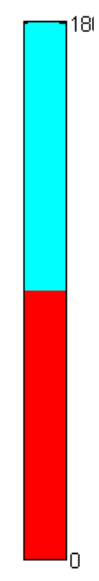

Fig. 5. Unifocal layouts of dual-band TA computed at (a) $29 \mathrm{GHz}$ and (b) 19.5 $\mathrm{GHz}$ respectively. The unit-cell is the same as for the bifocal TA.

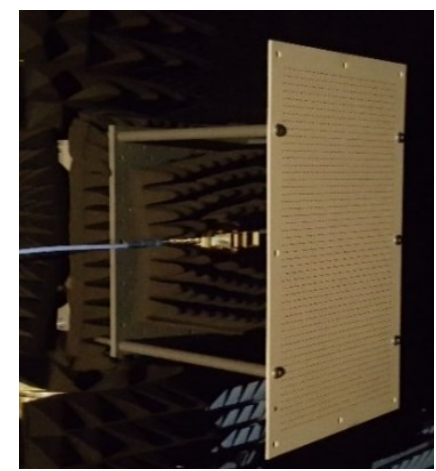

(a)

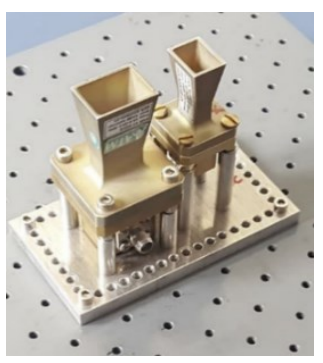

(b)
Fig. 6. Bifocal dual-band TA antenna mounted in IETR anechoic chamber. (a) TA panel. (b) Dual-feed horn focal array.

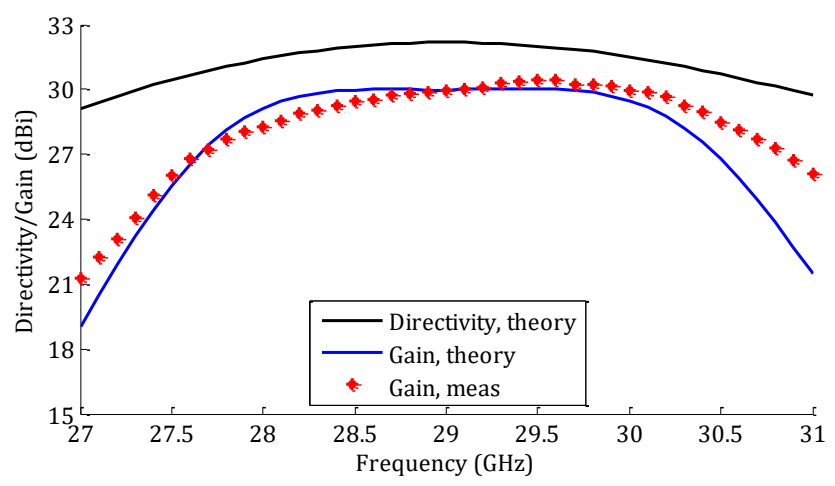

(a)

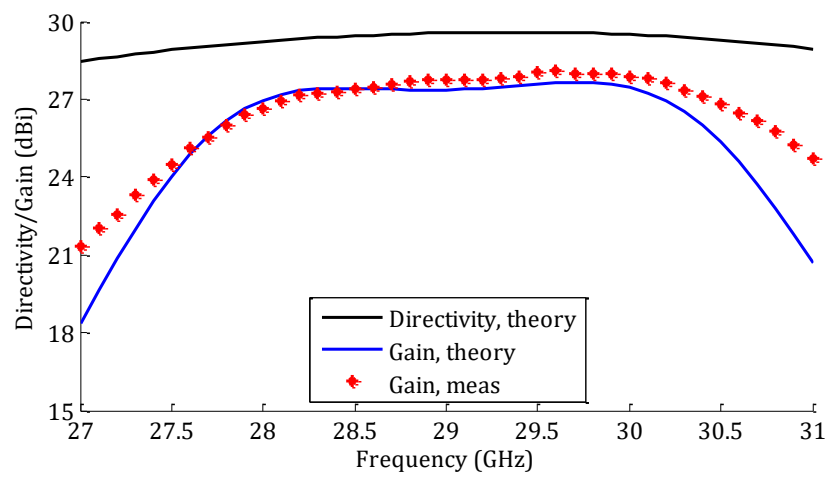

(b)

Fig. 7. Directivity and gain as a function of frequency: (a) unifocal and (b) bifocal TAs in up-link.

Both prototypes have been fabricated and measured in the millimeter-wave far-field anechoic chamber at IETR. The bifocal prototype mounted on the receiving mast is shown in Fig. 6a. They have been measured individually, using in both cases exactly the same feeding system with sliding horns (Fig. 6b). In the following results, as the TA prototypes are too large to be modeled using commercial electromagnetic solvers (like Ansys HFSS or CST) in affordable simulation times, all theoretical data have been obtained with our inhouse CAD tool, previously validated successfully in a number of publications, e.g. [4], [11], [12]. 


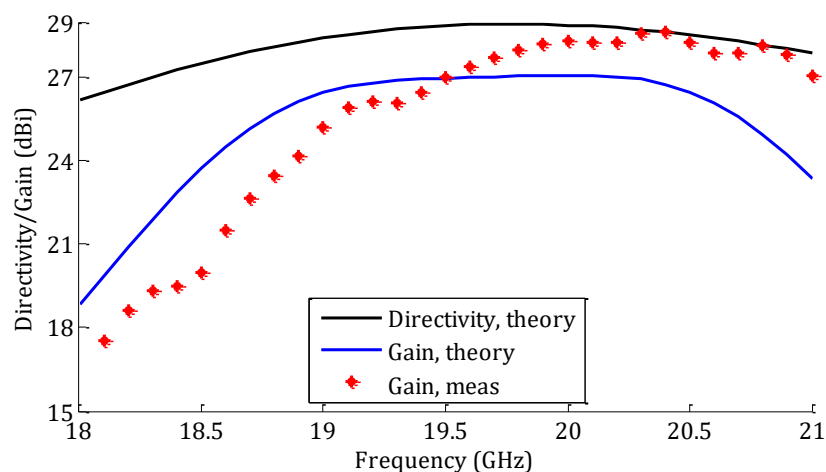

(a)

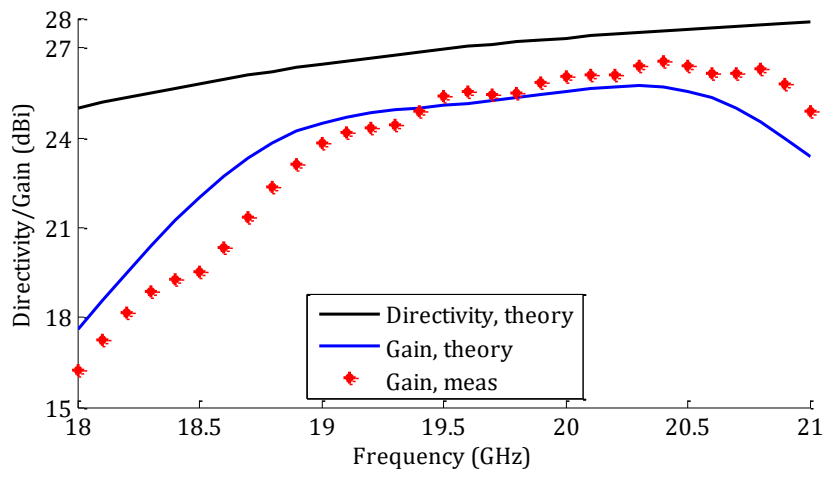

(b)

Fig. 8. Directivity and gain as a function of frequency: (a) unifocal and (b) bifocal TAs in down-link.

\section{A. Frequency Response and Patterns at Broadside}

Fig. 7 and Fig. 8 show the directivity and gain of the unifocal and bifocal TAs in up- and down-links, respectively. A good agreement between theoretical and measured gain values is observed in both bands.

In the up-link band, the measured $-1-\mathrm{dB}$ and $-3-\mathrm{dB}$ bandwidth (BW) of the bifocal prototype equal $7.6 \%(28.2 \mathrm{GHz}-30.4 \mathrm{GHz})$ and $11.7 \%$ $(27.6 \mathrm{GHz}-31 \mathrm{GHz})$, respectively. In the unifocal case, the -1 and 3-dB BWs are slightly smaller, namely, $6 \%(28.6 \mathrm{GHz}-30.3 \mathrm{GHz})$ and $10 \%(27.8 \mathrm{GHz}-30.7 \mathrm{GHz})$, respectively. Similar conclusions can be drawn for the down link: the $-1-\mathrm{dB}$ and $-3-\mathrm{dB}$ measured gain BWs of unifocal TA span from $19.7 \mathrm{GHz}$ to $20.9 \mathrm{GHz}$ and $19.1 \mathrm{GHz}$ to $21.2 \mathrm{GHz}(10.8 \%$ around $19.5 \mathrm{GHz})$ respectively, whereas the -3 $\mathrm{dB}$ bandwidth of the bifocal TA spans between $18.9 \mathrm{GHz}$ and 21.2 $\mathrm{GHz}(11.8 \%)$.

Due to the extension of the array dimension along the y-axis, the gain values at boresight of the up- and down-link unifocal TAs presented here $(30 \mathrm{dBi}$ at $29 \mathrm{GHz}$ and $27 \mathrm{dBi}$ at $19.5 \mathrm{GHz}$, respectively) are larger than the gains reported in [6] by about $1.2 \mathrm{~dB}$.

The normalized calculated radiation patterns are almost superimposed with the measured ones. For brevity purposes, we only provide the results in the scan plane at the center frequency in each case (H-plane at $29 \mathrm{GHz}$ in Fig. 9a, and E-plane at $19.5 \mathrm{GHz}$ in Fig. $9 b)$. In both cases, the measured side-lobe level (SLL) is in very good agreement with the simulated one.

The simulated results have been obtained using array theory, e.g. [11]; in particular, this simplified model uses the unit-cell characteristics computed in a purely periodic environment (Floquet mode analysis) as input data; moreover, it does not account for truncation and illumination effects. Despite these approximations, the agreement between the simulated and measured gains is very satisfactory (Fig. 7 and Fig. 8).

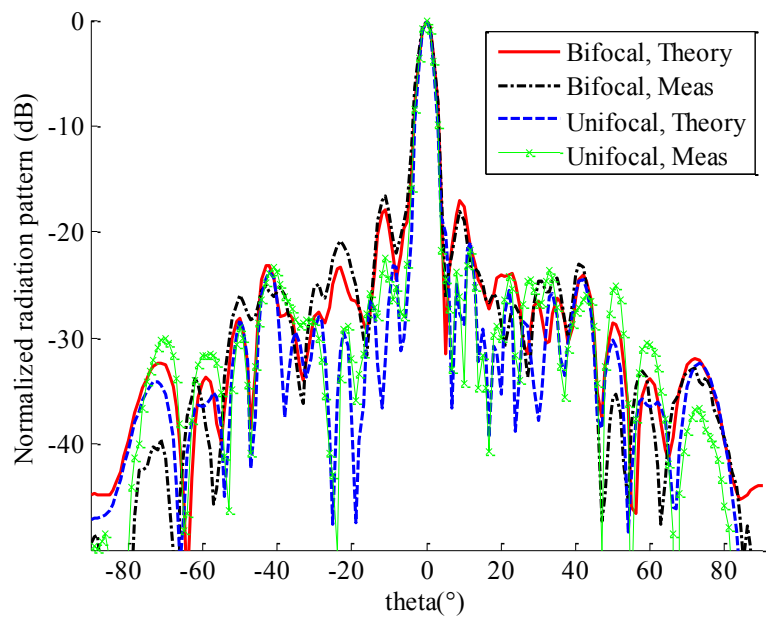

(a)

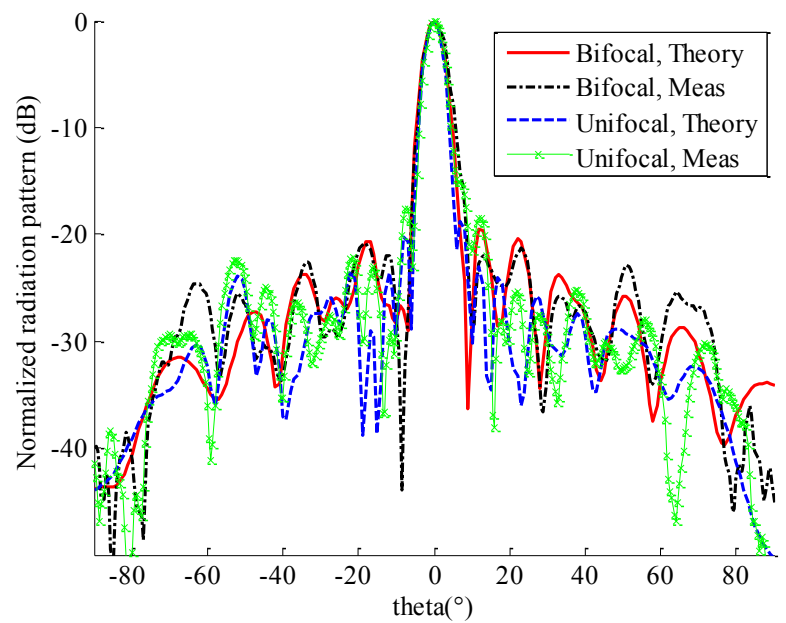

(b)

Fig. 9. Computed and measured radiation patterns (a) in H-plane at $29 \mathrm{GHz}$ and (b) in E-plane at $19.5 \mathrm{GHz}$.

\section{B. Performance in Scanning}

The performance in scanning of both prototypes has been measured by translating the feed horn base along focal lines in either down- or up-link, as schematized in Fig. 1. In practice, two successive feed positions are separated by $10 \mathrm{~mm}$, and they vary up to $80 \mathrm{~mm}$ from the center position (Fig. 6b) in both directions to check beam symmetry.

The collection of beam patterns measured for various horn positions is shown in Fig. 10 (up-link) and Fig. 11 (down-link) for the bifocal prototype. In all figures, the tilted beams are normalized to the maximum gain value measured at boresight. At $29.5 \mathrm{GHz}$, when the feed horn is moved from $-70 \mathrm{~mm}$ to $+70 \mathrm{~mm}$, the main beam is tilted from $-32^{\circ}$ to $33^{\circ}$ with a scan loss lower than $2 \mathrm{~dB}$. The total scan range reaches $60^{\circ}$ for a scan loss better than $1 \mathrm{~dB}$ (Fig. 10b). The SLL is less than $-11 \mathrm{~dB}$ for all beams in this range (Fig. 10a). Theoretical calculations are in very good accordance with measurement results, except for some beams at wide angle (see Fig. 10a); this is possibly due to the horn fixture, effect of oblique incidence and the edge 
diffraction that are not taken into account when computing the radiation patterns.

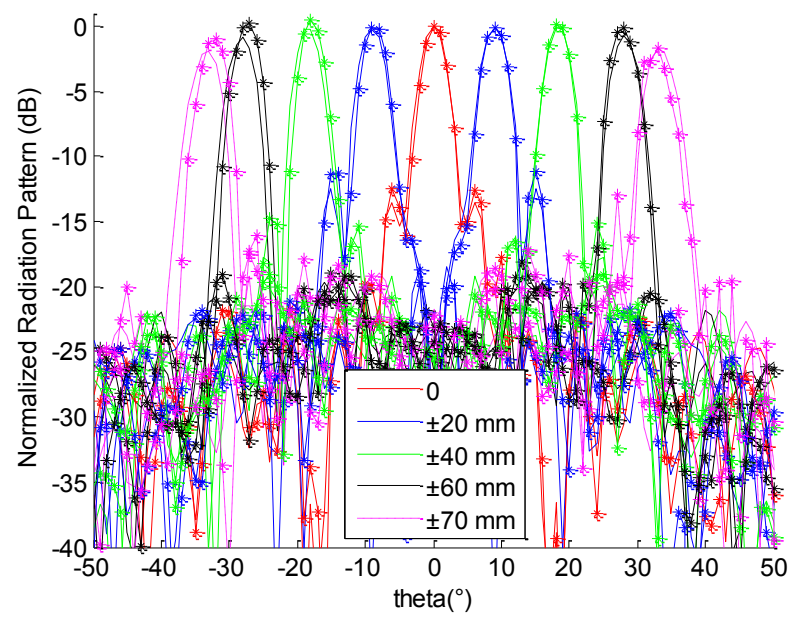

(a)

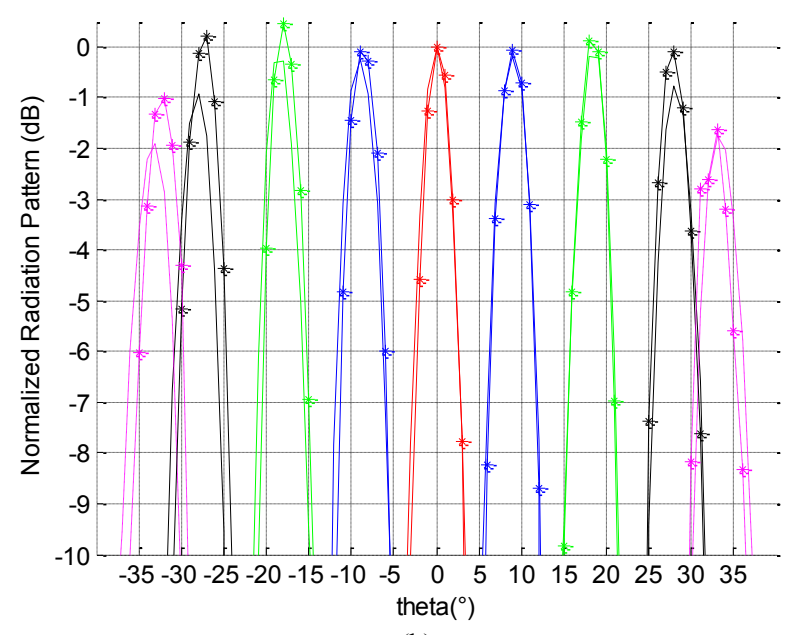

(b)

Fig. 10. Computed and measured radiation patterns of bifocal TA, for different beam pointing directions, at $29 \mathrm{GHz}$ in E-plane. (a) Results obtained for a wide range of elevation angle, (b) zoom close to the main beams. Curves with makers correspond to experimental results. All curves are normalized to the maximum gain at boresight.

Similar results have been obtained in the down link at $19.5 \mathrm{GHz}$ as shown in Figs. 11a and 11b. As the unit-cell is electrically smaller in this band, the scan range is slightly improved and reaches $80^{\circ}$ (horn displacement of $80 \mathrm{~mm}$ ) with a maximum gain drop of only $2 \mathrm{~dB}$ at $\pm 40^{\circ}$ (see Fig. 11b). The scan loss remains smaller than $1 \mathrm{~dB}$ loss for a field of view of $\pm 30^{\circ}$. Although not reported for brevity purposes, a very good agreement between measured and simulated patterns has been obtained for all beam positions across the $3 \mathrm{~dB}$ bandwidth.

As shown in Fig. $4 b$, the scanning performance obtained by translating the feed-horn in the bifocal down-link TA is better than the scanning obtained by the methods described in [6] (Section IV.C, Fig.19).

The unifocal dual-band TA has been also fully characterized for various horn positions, using the same experimental setup. As expected, our results indicate that the performance in scanning suffers from much larger scan loss (Fig. 12). A detailed analysis shows that the scan loss reaches $3.7-\mathrm{dB}$ at $\pm 18^{\circ}$, and that it drops sharply beyond
(5-dB at $\pm 25^{\circ}$ ), thereby confirming the considerable improvement in scanning of the bifocal approach.

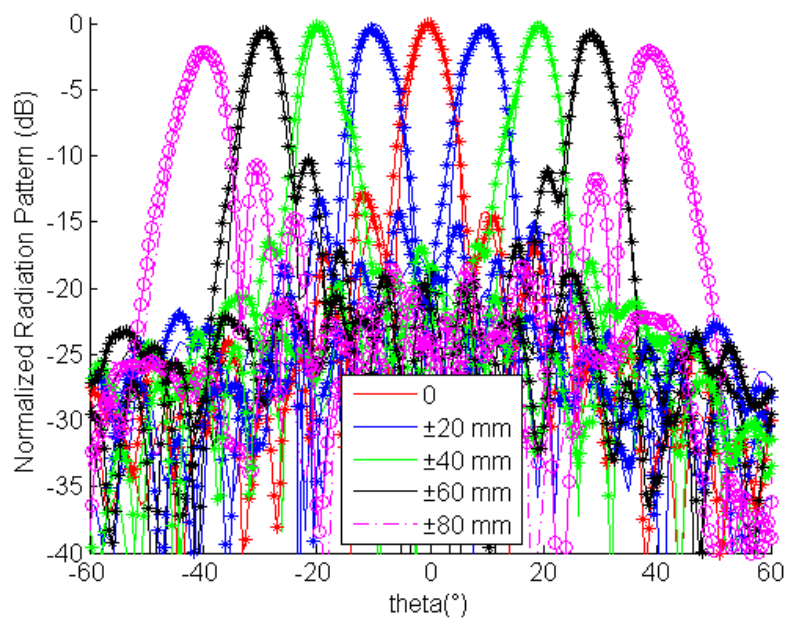

(a)

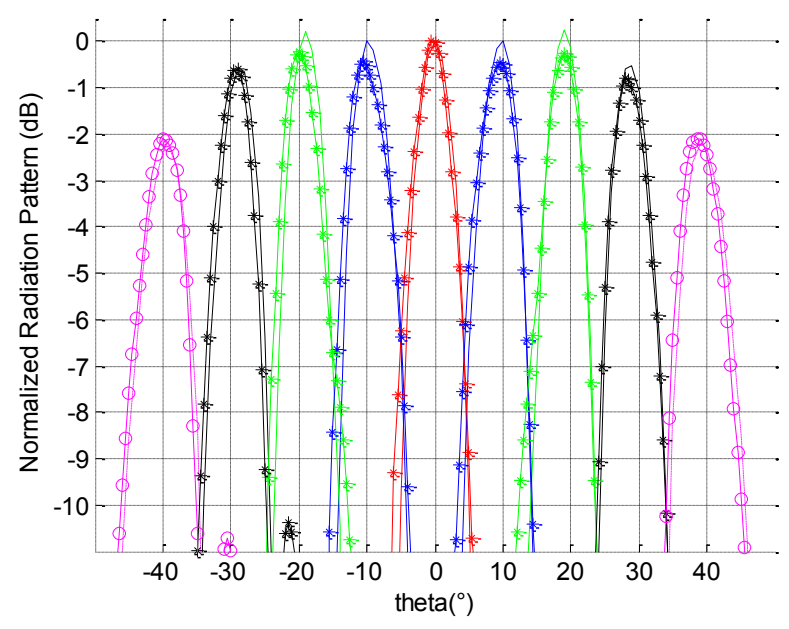

(b)

Fig. 11. Computed and measured radiation patterns of bifocal TA, for different beam pointing directions, at $19.5 \mathrm{GHz}$ in H-plane. (a) Results obtained for a wide range of elevation angle, (b) zoom close to the main beams. Curves with markers correspond to experimental results. All curves are normalized to the maximum gain at boresight.

A summary of recent results obtained at Ka-band with beam steerable transmitarray and reflectarray antennas is provided in Table II. It is obvious that this work provides a very wide field of view for both up- and down-link Ka-band with independent radiations.

TABLE II

PERFORMANCE IN SCANNING FOR VARIOUS BIFOCAL REFLECTARRAY AND TRANSMITARRAY PROTOTYPES AT KA-BAND.

\begin{tabular}{c|c|c|c}
\hline \hline Ref., type & Frequency $(\mathrm{GHz})$ & Scan. Range $($ deg. $)$ & Loss $(\mathrm{dB})$ \\
\hline \multirow{2}{*}{$\begin{array}{c}\text { This work } \\
\text { TA }\end{array}$} & 29 & $65^{\circ}\left(-32^{\circ}-35^{\circ}\right)$ & 2.0 \\
\cline { 2 - 4 } & 19.5 & $80^{\circ}\left( \pm 40^{\circ}\right)$ & 2.0 \\
\hline \multirow{2}{*}{ [7], TA } & 30 & $50^{\circ}\left(0^{\circ}-50^{\circ}\right)$ & 3.3 \\
\cline { 2 - 4 } & 20 & $50^{\circ}\left(0^{\circ}-50^{\circ}\right)$ & 3.6 \\
\hline [19], TA & 30 & $50^{\circ}\left(0^{\circ}-50^{\circ}\right)$ & 2.8 \\
\hline [20], TA & 30 & $40.4^{\circ}\left(16.1^{\circ}-56.5^{\circ}\right)$ & 2.4 \\
\hline [18], RA & 32 & $60^{\circ}\left( \pm 30^{\circ}\right)$ & 0.75 \\
\hline \hline
\end{tabular}




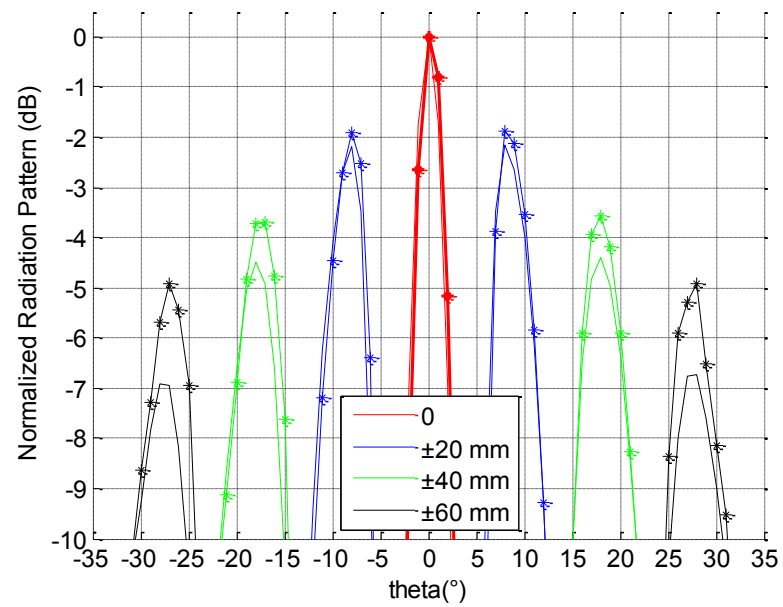

(a)

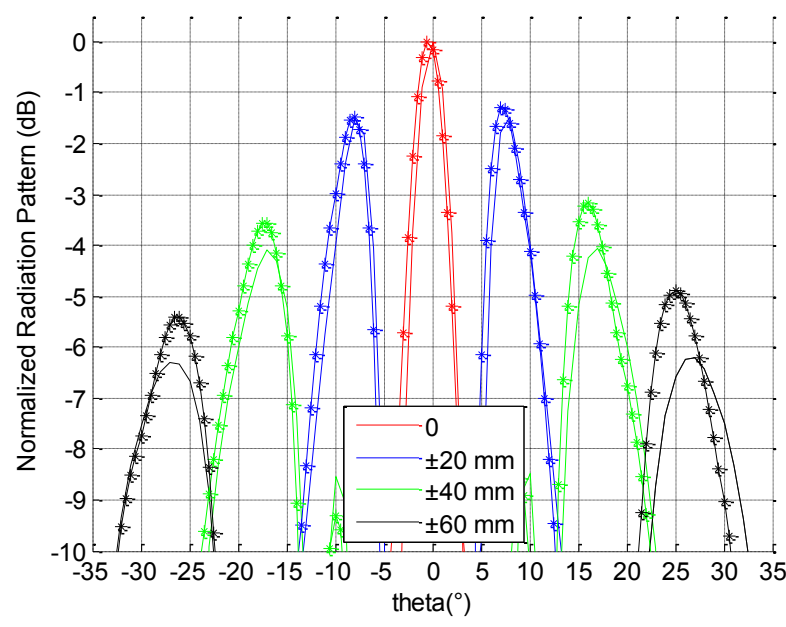

(b)

Fig. 12. Computed and measured radiation patterns of unifocal TA, for different beam pointing directions, (a) at $29 \mathrm{GHz}$ in E-plane and (b) at 19.5 $\mathrm{GHz}$ in the H-plane. Curves with markers correspond to experimental results. All curves are normalized to the maximum gain at boresight. The reported results are zoomed close to the main beam to better appreciate the scan loss level, as compared to bifocal designs (Figs. 10 and 11).

\section{CONCLUSION}

The paper has demonstrated experimentally independent scanning of transmitarray antennas in up- and down-links at Ka-band. Two prototypes have been fully characterized to validate their scanning capabilities. Both operate in dual-band (their design relies on the interleaving technique), and one of them exhibits two focal points in each band to extend its maximum scanning range. Our results show that it is possible to scan the TA beam over $80^{\circ}$ and $60^{\circ}$ in elevation, with only $2-\mathrm{dB}$ of loss at $19.5 \mathrm{GHz}$ and $29 \mathrm{GHz}$ respectively. Indeed, the wide beam scanning provided by this architecture, with two independent beams operating in different frequency bands, makes it an excellent candidate for SOTM applications or for $5 \mathrm{G}$ applications.

\section{ACKNOWLEDGMENTS}

This work has been partly supported by the European Union through the European Regional Development Fund (ERDF), and also by Ministry of Higher Education and Research, Brittany and Rennes Métropole, through the CPER Project SOPHIE/STIC \& Ondes.
[1] R. Pearson, "Next generation mobile SATCOM terminal antennas for a transformed world," $5^{\text {th }}$ Eur. Conf. Antennas Propag., Rome, Italy, Mar. $11-15,2011$

[2] S. B. Yeap, X. Qing, and Z. N. Chen, "77-GHz dual-layer transmit-array for automotive radar applications," IEEE Trans. Antennas Propag., vol. 63, no. 6, pp. 2833-2837, Jun. 2015.

[3] K. Pham, N. T. Nguyen, A. Clemente, L. Di Palma, L. Le Coq, L. Dussopt, and R. Sauleau, "Design of wideband dual linearly-polarized transmitarray antennas," IEEE Trans. Antennas Propag., vol. 64, no. 5, pp. 2022-2026, May 2016.

[4] F. Diaby, A. Clemente, K. T. Pham, R. Sauleau, and L. Dussopt, "Circularly polarized transmitarray antennas at Ka-band," IEEE Antennas Wireless Propag. Lett., vol. 17, no. 7, pp. 1204-1208, Jul. 2018.

[5] H. Kaouach, L. Dussopt, J. Lantéri, R. Sauleau, and T. Koleck, "Wideband low-loss linear and circular polarization transmitarray in Vband," IEEE Trans. Antennas Propag., vol. 59, no. 7, pp. 2513-2523, Jul. 2011.

[6] K. Pham, R. Sauleau, E. Fourn, F. Diaby, A. Clemente, and L. Dussopt, "Dual-band transmitarrays with dual-linear polarization at Ka-band," IEEE Trans. Antennas Propag., vol. 65, no. 12, pp. 7009-7018, Dec. 2017.

[7] S. A. Matos, E. B. Lima, J. S. Silva, J. R. Costa, C. A. Fernandes, N. J. G. Fonseca, and J. R. Mosig, "High gain dual-band beam-steering transmit array for satcom terminals at Ka-band," IEEE Trans. Antennas Propag., vol. 65, no. 7, pp. 3528-3539, Jul. 2017.

[8] R. Y. Wu, Y. B. Li, W. Wu, C. B. Shi, and T. J. Cui, "High-gain dualband transmitarray," IEEE Trans. Antennas Propag., vol. 65, no. 7, pp. 3481-3488, Jul 2017.

[9] K. T. Pham, A. Clemente, E. Fourn, F. Diaby, L. Dussopt, and R. Sauleau, "Low-cost metal-only transmitarray antennas at Ka-Band," IEEE Antennas Wireless Propag. Lett., vol. 18, no. 6, pp. 1243-1247, Jun. 2019.

[10] J. Y. Lau and S. V. Hum, "Reconfigurable transmitarray design approaches for beamforming applications," IEEE Trans. Antennas Propag, vol. 60, no. 12, pp. 5679-5689, Dec. 2012.

[11] A. Clemente, L. Dussopt, R. Sauleau, P. Potier, and Ph. Pouliguen, "Wideband 400-element electronically reconfigurable transmitarray in X band," IEEE Trans. Antennas Propag., vol. 61, no. 10, pp. 5017-5027, Oct. 2013.

[12] L. Di Palma, A. Clemente, L. Dussopt, R. Sauleau, P. Potier, and P. Pouliguen, "Circularly-polarized reconfigurable transmitarray in Kaband with beam scanning and polarization switching capabilities," IEEE Trans. Antennas Propag., vol. 65, no. 2, pp. 529-540, Feb. 2017.

[13] F. Yang, S. Xu, X. Pan, X. Yang, J. Luo, M. Wang, Y. Wang, and M. Li, "Reconfigurable reflectarrays and transmitarrays: From antenna designs to system applications," 12th Eur. Conf. Antennas Propag., London, UK, Apr. 9-13, 2018.

[14] H. Yang, F. Yang, X. Cao, S. Xu, J. Gao, X. Chen, M. Li, and T. Li, “A 1600 -element dual-frequency electronically reconfigurable reflectarray at X/Ku-Band," IEEE Trans. Antennas Propag., vol. 65, no. 6, pp. 30243032, Jun. 2017.

[15] L. Dussopt A. Moknache, J. Sailly, A. Lamminen, M. Kaunisto, J. Aurinsalo, T. Bateman, and J. Francey, "A V-band switched-beam linearly polarized transmit-array antenna for wireless backhaul applications," IEEE Trans. Antennas Propag., vol. 65, no. 12, pp. 67886793, Dec. 2017.

[16] Y. Hou, L. Chang, Y. Li, Z. Zhang, and Z. Feng, "Linear multibeam transmitarray based on the sliding aperture technique," IEEE Trans. Antennas Propag., vol. 66, no. 8, pp. 3948-3958, Aug. 2018.

[17] G. Wu, S. Qu, and S. Yang, "Wide-angle beam-scanning reflectarray with mechanical steering," IEEE Trans. Antennas Propag., vol. 66, no. 1, pp. 172-181, Jan. 2018

[18] P. Nayeri, F. Yang, and A. Z. Elsherbeni, "Bifocal design and aperture phase optimizations of reflectarray antennas for wide-angle beamscanning performance," IEEE Trans. Antennas Propag., vol. 61, no. 9, pp. 4588-4597, Sep. 2013.

[19] E. B. Lima, S. A. Matos, J. R. Costa, C. A. Fernandes, and N. J. G. Fonseca, "Circular polarization wide-angle beam steering at Ka-band by in-plane translation of a plate lens antenna," IEEE Trans. Antennas Propag.,vol. 63, no. 12, pp. 5443-5455, Dec. 2015.

[20] S. A. Matos, E. B. Lima, J. R. Costa, C. A. Fernandes, and N. J. G. Fonseca, "Design of a $40 \mathrm{dBi}$ planar bifocal lens for mechanical beam steering at Ka-band," 10th Eur. Conf. Antennas Propag., Davos, Switzerland, Apr. 10-15, 2016. 